\title{
Los exempla paganos en la literatura polémica cristiana: la figura de Dido
}

\author{
Luis Pomer Monferrer \\ Universitat de València \\ luis.pomer@uv.es
}

Según una tradición antevirgiliana que influyó en la Europa medieval y persistió vigorosamente en el Siglo de Oro español, Dido se suicidó para no ceder a las demandas de un segundo matrimonio de Jarbas, el rey de los libios, que insistentemente la requería en matrimonio ${ }^{1}$. Esta tradición, que o bien hace caso omiso de Virgilio, o le acusa implícita o explícitamente de falsario, ensalza la castidad de Dido, la viuda que, por fidelidad a su primer marido Siqueo, llega hasta el suicidio, cuidadosa y hábilmente premeditado, preparado y ejecutado, para no ceder a una nueva unión conyugal o, lo que es lo mismo para la época, amorosa. El arraigo de tal versión en España se debe a Justino, que en su resumen de las Historias Filípicas de Trogo Pompeyo presenta a una Dido casta, fiel a la memoria de su marido muerto, y consagrada a la fundación y organización de la ciudad de que es reina, donde llegará a ser adorada como una diosa ${ }^{2}$. Esta versión de Justino penetra, al mismo tiempo que las conocidas de la Eneida y las Heroidas de Ovidio, en las fuentes más importantes de recepción y transmisión de la materia romana en la Península Ibérica como son la Crónica General alfonsí y a través de ella las Sumas de Historia Troyana atribuidas a Leomarte y popularizadas a través de la Crónica Troyana impresa en $1490^{3}$. Pero también existe una tradición cristiana de la versión que tuvo gran influencia en la Península Ibérica a través de Jerónimo principalmente $^{4}$ : la figura de una Dido que se sacrifica por no volver a casarse es un buen ejemplo de la Antigüedad para destacar el rechazo que los primeros Padres de la Iglesia mostraron ante las segundas nupcias, que se enmarca en la defensa del ascetismo por parte de toda una extensa serie de obras de carácter doctrinal ${ }^{5}$.

\footnotetext{
${ }^{1}$ La formulación más antigua se encuentra en un fragmento de la Historia de Sicilia e Italia de Timeo (340256 a.C.). Cfr. M.R. Lida de Malkiel, Dido en la literatura española, London, 1974, p. 57; R. González Cañal, «Dido y Eneas en la poesía española del Siglo de Oro», Criticón 44 (1988), pp. 25-54.

${ }^{2}$ Iust. $18,6,5-8$.

${ }^{3}$ R. González Cañal, op. cit., p. 26.

${ }^{4}$ Sobre la importancia de Jerónimo en la Edad Media hispana y la transmisión de su obra a través de florilegios, cfr. A.M. Aldama, «Operis mei est et studii multos legere. Jerónimo en el Medioevo», RELat 3 (2003) pp. 119-132.

${ }^{5}$ Sobre la condición de la viuda dedicada a Dios, $c f r$. R. Navarro Sáez «La mujer al final de la Antigüedad: las viudas profesas», en L.G. Luna (ed.), Mujeres y sociedad. Nuevos enfoques teóricos y metodológicos, Barcelona, 1991, pp. 111-121.
} 
Pero no todos los autores cristianos hacen uso de ejemplos de la Antigüedad grecolatina, pese a ser la cultura en la que se educaron, pues la conveniencia de emplear modelos paganos era motivo de discusión entre los escritores cristianos. El siglo IV es el momento clave del conflicto entre el pensamiento grecorromano y el cristiano, pues se dudaba que de algo intrínsecamente negativo como el paganismo pudiera extraerse algún provecho para la doctrina cristiana: según esta visión, el espíritu y los ideales del cristianismo estaban en oposición con los de los rétores y escritores paganos, pues para el cristiano toda ciencia y toda cultura estriba en la Biblia. Y es que los primeros adeptos del cristianismo eran en general hombres de escaso bagaje cultural, pero los Padres de la Iglesia, tanto de Oriente como de Occidente, son en su mayoría rhetores que se han formado en las escuelas paganas y que, más o menos voluntaria y conscientemente, utilizan los recursos de la retórica clásica como instrumento para la transmisión del Evangelio, puesto que no pueden librarse fácilmente de una formación eminentemente clásica ${ }^{6}$.

Las críticas rigoristas más contrarias a la utilización de los paganos son más aparentes que reales, pues aquellos que se sirven de ellas están formados en la retórica clásica y, en general, en la cultura pagana, ya que era la única fuente de la que podían beber los autores cristianos para redactar sus escritos, como ocurre por ejemplo con Tertuliano $^{7}$, pese a sus famosas soflamas antiprofanas ${ }^{8}$, o con Taciano, el único de los apologistas griegos que propugna por principio el repudio total de la filosofía y, en general, de toda la civilización helenística ${ }^{9}$ : ¿Qué habéis producido que merezca respeto, con vuestra filosofía? ¿Quién de entre los que pasan por los más notables estuvo exento de arrogancia? ... Pues filosofen en hora buena tales gentes» ${ }^{10}$.

Sin embargo, una cosa es la influencia que los autores paganos ejercieron sobre los cristianos porque eran los únicos modelos de que disponían, especialmente en los primeros tiempos, ya que la cultura de su época era una cultura profana y la retórica que utilizaban era la aprendida en las escuelas paganas de los rhetores, y otra cosa muy diferente es utilizar a los paganos como modelos de comportamiento a seguir por los cristianos, pues este papel estaba asignado a los exempla cristianos, extraídos principalmente de la Sagrada Escritura; los paganos, por su parte, «ayudan a mostrar la novedad de la vida sobrenatural que ha traído Cristo» ${ }^{11}$.

\footnotetext{
${ }^{6}$ Para la influencia de la retórica clásica en los autores cristianos, $c f r$. G.A. Kennedy, A new history of classical rhetoric, Princeton, 1994, pp. 257-270.

${ }^{7}$ Cfr. A. Labhardt, «Tertullien et la philosophie ou la recherche d'une 'position pure'», Museum Helveticum 7 (1950), pp. 150-180; J.C. Fredouille, Tertullian et la conversion de la culture antique, Paris, 1972.

${ }^{8}$ Apologeticum 46, 17-18 (ed. J.P. Waltzing - A. Severyns, Paris, Les Belles Lettres, 1961); De praescriptione haereticorum 7, 9-13, (ed. R.F. Refoulé, Paris, Éditions du Cerf, 1957).

${ }^{9}$ Cfr. B. Pouderon, Les apologistes grecs du II siècle, Paris, 2005, p. 81; J. Torres, «La retórica como arma de propaganda y persuasión en la literatura polémica cristiana», G. Bravo - R. González Salinero (eds.), Propaganda y persuasión en el mundo romano: Actas del VIII Coloquio de la Asociación Interdisciplinar de Estudios Romanos, 2011, pp. 269-278, esp. p. 270.

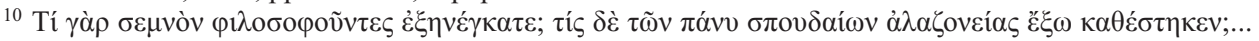

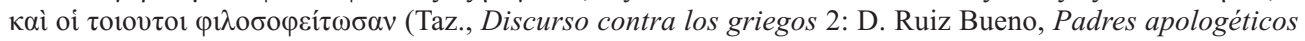
griegos, ed. y tr. esp., Madrid, 1979, pp. 574-575).

${ }^{11}$ F. Vera, Los exempla femeninos en San Ambrosio, Pamplona, 2003, p. 194.
} 


\section{TERTULIANO}

En las siguientes páginas voy a exponer el contexto en el que aparece citado el personaje de Dido en la obra de los autores cristianos, y el uso que hacen de su figura, empezando por Tertuliano, quien la menciona hasta en seis obras. En Ad Nationes 1, $18^{12}$, discurso apologético dirigido a los ciudadanos romanos en general, se sirve del recurso de la comparación para defender que también existen ejemplos en el mundo pagano de hombres y mujeres que han dado su vida por la virtud y no se les achaca su obstinatio o contemptus mortis, convirtiendo los argumentos habituales para la defensa del paganismo en argumentos para la ofensiva ${ }^{13}$. Tras exponer en los primeros capítulos que los paganos condenan a los cristianos por desconocimiento, refuta a continuación las calumnias habituales desarrollando una argumentación en la que los contrarios son llevados al absurdo y ellos mismos deben ser acusados. Este procedimiento retórico de la retorsión de los argumentos sirve para refutar las calumnias que les imputan los adversarios, es decir, para acusarlos de los mismos delitos que se achacan a los cristianos, de manera que si las acusaciones fueran verdaderas los paganos cometen delitos peores, lo que les deja sin argumentos para condenar los actos de los cristianos ${ }^{14}$. El mecanismo argumentativo de este pasaje es el siguiente: ¿cómo pueden los paganos criticar que los mártires ofrezcan su vida por sus ideales cuando tienen como héroes a personajes que actuaron de la misma manera por los suyos, como aquellos cuyas acciones se enumeran aquí? Entre los modelos del mundo antiguo, Tertuliano únicamente presenta a un hombre, Régulo ${ }^{15}$, el resto son ejemplos femeninos: la reina de Egipto (Cleopatra), Dido, la mujer de Asdrúbal, y una mujer ática que se arrancó la lengua con sus propios dientes y se la lanzó al tirano para no caer en la debilidad de confesar, episodio que hace referencia a Ifícrates y al tirano Hipias.

Puesto que su argumentación se basa en la comparación entre ambos mundos, las contraposiciones y antítesis son muy frecuentes. Tertuliano contrapone con frecuencia los adjetivos posesivos noster y vester para separar lo cristiano de lo pagano, así como los pronombres personales nos y vos. En la siguiente oración, que es la que mejor resume el razonamiento del apologeta africano, se contraponen los «vuestros» a los «nuestros», aplicándose a los primeros el sustantivo gloriam y a los segundos duritiam por los mismos hechos (ista): «Consideráis una hazaña para los vuestros lo que entre los nuestros llamáis terquedad $\gg^{16}$.

Tras la introducción en los dos primeros apartados donde expone los hechos y la presentación de los exempla paganos mencionados, Tertuliano utiliza con habilidad dos apóstrofes con imperativos dirigidos a los paganos para destacar la sinrazón de

\footnotetext{
12 Sigo la edición de J. W. Ph. Borleffs, CCSL 1, Turnhout, Brepols, 1954.

${ }^{13}$ Cfr. C. Ames, «La apología y el diálogo en los primeros apologistas latinos: Tertuliano y Minucio Félix», Circe 12 (2008), pp. 45-60, esp. p. 53.

${ }^{14}$ Cfr. J. Torres, op. cit., p. 274.

15 Sobre el suplicio de Régulo y los autores en que aparece citado, $c f r$. G. Minunno, «Remarques sur le supplice de M. Atilius Regulus», Les Études Classiques 73/3 (2005), pp. 217-234.

16 Tert. Ad nat. 1, 18, 5: Sed uestris ista ad gloriam, nostris ad duritiam deputatis.
} 
estos al calibrar con dos varas de medir los actos de unos y los de otros: «iDestruid la gloria de vuestros antepasados para destruirnos también a nosotros! ${ }^{17}$; y plantearles que, siguiendo el silogismo, si de lo que se trata es de impedir por todos los medios la concesión de la gloria a los cristianos, lo único que les falta es menoscabar las hazañas de sus antepasados para que no puedan compararse las de los cristianos con ellas: «iRetractaos también de las alabanzas que hasta el presente habéis dado a vuestros padres, para no tener que dárnoslas por lo mismo!» ${ }^{18}$. Estos apóstrofes están cargados de un fuerte acento retórico, al que coadyuvan la epanadiplosis en la primera exclamación, y las contraposiciones formales entre ambos mundos, el nuestro (nos, nobis), y el pagano, representado por aquellas palabras que los antiguos romanos empleaban para hablar de sus antepasados, maiores y parentum.

Recurre a continuación a la figura de la anticipación, procedimiento dialógico que plantea las objeciones que se supone pueden argüirse en contra de su razonamiento, como son las diferentes circunstancias cronológicas de ambas clases de ejemplos. En efecto, los paganos llevaron a cabo sus acciones en tiempos remotos que exigían el sacrificio, mientras los cristianos las realizan en tiempos de paz: «Podríais decirme que la dureza de los tiempos en que vivían vuestros ancestros reclamaba esta intrépida energía, mientras que ahora la tranquilidad de la paz exige costumbres más tranquilas y disposiciones más tolerantes incluso hacia los extranjeros» ${ }^{19}$.

El argumento anticipativo asignado a los contrarios va introducido por la forma verbal exegerit con el refuerzo forsitan. Diversos mecanismos léxicos antitéticos son reforzados por el uso de comparativos y repetición: antiquitatis / nunc; robustioris / tranquillitate; ingenia duriora / ingenia mitiora.

El razonamiento de los contrarios continúa introducido por un inquitis de sentido eventual y con abundancia de pronombres personales y posesivos que crean una tajante contraposición entre ambos mundos, el cristiano en primera persona y el pagano en segunda; estos no van a aceptar ninguna comparación por más lógica que resulte, ya que rechazan todo lo distinto, todo lo que no es suyo: «De acuerdo», diréis, «comparaos vosotros con los antiguos, para nosotros es necesario perseguiros con odio por cualidades que ni valoramos ni poseemos» ${ }^{20}$.

Tertuliano acaba el capítulo demostrando con ejemplos que los argumentos que ha atribuido a los paganos, y que son los únicos que podrían aducir en su favor, no son ciertos, lo que sirve para fundamentar la tesis en que se basa su argumentación: el obstinado desprecio a la muerte asignado a los cristianos no es considerado de la misma manera entre los paganos, pues también ellos continúan despreciando a la muerte en los tiempos actuales de paz, lo que sirve para refutar las acusaciones de que son víctimas los cristianos. Así, en los actuales tiempos los paganos, aunque ahora ya no hay ejemplos como

\footnotetext{
17 Ibidem: Destruite nunc gloriam maiorum, quo nos quoque destruatis!

18 Ibidem: Contenti estote detrahere etiam laudi parentum ad praesens, ne nobis locum detis!

${ }^{19}$ Ibidem, 1, 18, 6: De his forsitan et temporum qualitas robustioris antiquitatis exegerit ingenia duriora, at nunc tranquillitate pacis et ingenia mitiora et mentes hominum etiam in extraneos piae.

${ }^{20}$ Ibidem, 1, 18, 7: «Esto», inquitis, «ueteribus uos comparate; nobis necesse est in uobis odio pro sequi, quod a nobis non probatur, quia nec inuenitur in nobis».
} 
los antiguos, siguen ofreciendo sus vidas a la espada de los gladiadores «no por amor a la vida ${ }^{21}$, siguen enrolándose en el ejército «y no por temor a la muerte $»^{22}$, se entregan voluntariamente a las bestias «diariamente en tiempos de paz» ${ }^{23}$, se cubren con «una túnica encendida» ${ }^{24}$, o desafían los golpes en espectáculos circenses ${ }^{25}$.

Como puede observarse, la retorsio argumentorum de Tertuliano tiene un carácter silogístico, o por mejor decir, de ruptura de silogismos: si los ejemplos de los antepasados de desprecio a la muerte son modelo de virtud para los paganos, ¿por qué no lo son los ejemplos actuales de los cristianos? Si los ejemplos presentes de los cristianos no son válidos porque en estos momentos de paz no tienen sentido, ¿por qué los paganos siguen despreciando a la muerte en la actualidad de una manera semejante a como lo hacían sus mayores? Dicho de otro modo: el desprecio a la muerte es un modelo de virtud; los héroes paganos desprecian la muerte; luego son modelos de virtud, argumento que, en cambio, no vale para los cristianos. El desprecio a la muerte en tiempos de paz no tiene sentido; los paganos desprecian la muerte en tiempos de paz; luego no tiene sentido que los paganos desprecien la muerte actualmente como hacen los cristianos, a no ser que la premisa principal sea falsa.

El Apologeticum es la obra más conocida de Tertuliano, y a diferencia del Ad nationes, que parece más una colección de materiales que una obra acabada, tiene la estructura de un discurso judicial dirigido a los gobernadores de las provincias romanas, siguiendo el esquema clásico, si bien en lugar de la narratio se halla la causa en la que se discute la ley que castiga a los cristianos en la persecución ${ }^{26}$. La cita de Dido está situada en el último capítulo de la obra, el 50, que siguiendo el esquema del discurso sería la peroratio, que trata de la victoria en los tormentos de los cristianos. La estructura de este capítulo es la que sigue: una recapitulación teórica sobre lo que significa la victoria para los cristianos (1-4); la presentación de exempla de héroes paganos (49); una llamada a la indignación por la injusticia que representa el diferente trato de estos héroes y el de los cristianos (10-11); la parte final, poblada de apóstrofes a los jueces, en lugar de la llamada a la piedad, característica del epílogo de un discurso judicial, sigue incitando la indignación y la cólera por la injusticia de la actuación de los jueces -los gobernadores de las provincias-, haciendo referencia al sufrimiento y la muerte que causan, que de nada sirven contra los cristianos, porque siguen una verdad manifestada por Dios (12-16).

Al igual que en Ad nationes, Tertuliano enumera una serie de paganos que son tomados como modelos por su valentía y su comtemptum mortis, respuesta que ofrece Zenón de Elea al tirano Dionisio cuando este le pregunta quidnam philosophia praestaret «de qué servía la filosofía» (Tert. Apologeticum 50, $9^{27}$ ), y que le costó la muerte, si

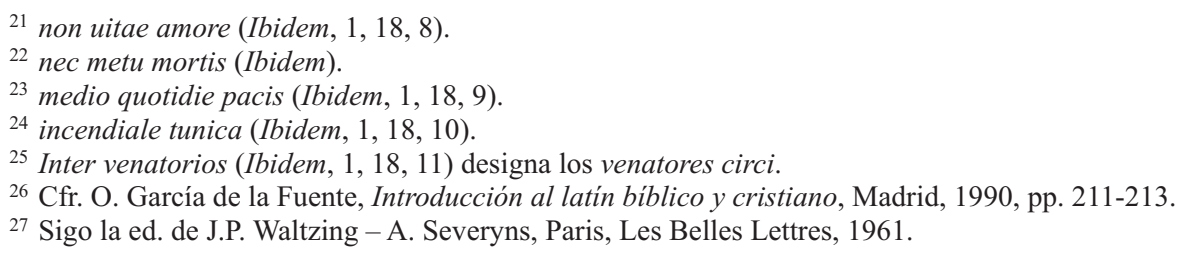


bien el tirano de la anécdota, conocida por la Vida de los filósofos ilustres de Diógenes Laercio, no es Dionisio de Siracusa, un siglo posterior al filósofo. La lista repite varios de los personajes antes mencionados, la propia Dido, Régulo, la Attica meretrix que es la misma mulier Attica de la cita previa, además de los jóvenes lacedemonios que se flagelaban en el templo de Diana, a los que se hace una escueta referencia en el texto anterior: ut taceam de Laconica gloria, «dejemos de lado la gloria lacedemonia» (Tert. Ad nationes $1,18,11$ ) 28 ; y añade tres conocidos personajes, Mucio Escévola, Empédocles y Anaxarco. Cada uno de estos personajes es admirado por una cualidad de la que es exemplum, para lo que Tertuliano utiliza el apóstrofe: $O$ praeconium castitatis! dice de la Carthaginis conditrix, como llama a Dido (Tert. Apologeticum 50, 5); O sublimitas animi! de Mucio, famoso por haberse quemado la mano derecha en el altar voluntariamente ante la amenaza de tortura del etrusco Porsena (Ibidem); O uigor mentis! de Empédocles, por arrojarse al Etna (Ibidem); O uirum fortem et in captiuitate uictorem! de Régulo, torturado por los cartagineses en una cuba llena de púas de acero (Ibidem, 50, 6); O philosophi magnanimitatem, qui de tali exitu suo etiam iocabatur! de Anaxarco, que se burlaba de Nicrocreonte, tirano de Chipre, cuando era majado como si fuera a ser servido como comida al pueblo (Ibidem).

Como en la cita anterior, Tertuliano emplea como recurso retórico antítesis que destacan la diferente -y en consecuencia injusta- consideración que merecen los ejemplos paganos y los cristianos, y como allí, relaciona los argumentos positivos con los pronombres-adjetivos de primera persona y los negativos con los de segunda, un buen ejemplo de lo cual es la frase «pues vuestra maldad es prueba de nuestra inocencia» ${ }^{29}$. Toda la peroratio final destaca esa injusticia, que llega el sarcasmo cuando califica como buenos a los jueces y los anima a continuar con el tormento de los cristianos: «Pero actuad así, presidentes buenos, mucho mejores ante el pueblo si en su honor habéis inmolado a los cristianos, atormentadnos, torturadnos, condenadnos, trituradnos ${ }^{30}$.

Sirve para destacar la acción de los cristianos la paradoja entre muerte y victoria, oxímoron que va acompañado de otros recursos como la figura etimológica y la epanadiplosis: «Pero somos apresados. Sí, cuando hemos triunfado. Luego vencemos cuando se nos mata, y escapamos cuando se nos prende ${ }^{31}$. Abundan las repeticiones expresivas, como omni poena et omni morte (Ibidem, 50, 12), o juegos de palabras, por ejemplo con los diferentes significados del verbo patior en Ideo nos haec pati deus patitur (ibidem), o con la homofonía lenonem / leonem: proxime ad lenonem damnando Christianam potius quam ad leonem (ibidem), pues en aquellos días una noble cristiana fue llevada a un prostíbulo para castigarla, como sucedió con Santa Inés, porque eso suponía un tormento más cruel para ella que ser llevada ante las fieras.

\footnotetext{
${ }^{28}$ Se trata del certamen de los mozos de Lacedemonia en la fiesta de Diana Ortia en el que vencía quien más sangre derramaba, llegando a morir algunos por motivo de los azotes.

29 Tert. Apol. 50, 12: probatio est enim innocentiae nostrae iniquitas uestra.

${ }^{30}$ Ibidem: Sed hoc agite, boni praesides, meliores multo apud populum, si illis Christianos immolaueritis, cruciate, torquete, damnate, atterite nos.

31 Ibidem, 50, 3: Sed obducimur. Certe, cum obtinuimus. Ergo uicimus, cum occidimur, denique euadimus, cum obducimur.
} 
Tertuliano utiliza el recurso propio de la peroratio de llamar a la indignación al auditorio por la injusticia que representa el diferente trato de una misma acción según quien la realice sea pagano o cristiano: «iOh gloria lícita por ser humana, que está permitido que la consiga el sufrimiento por la patria, por el imperio, por la amistad, mientras que por Dios no es lícito!» ${ }^{32}$. Esta injusticia viene realzada por la antítesis entre permissum est y non licet. $\mathrm{Y}$ el argumento consecuente insiste en el mismo contraste injusto, ya que mientras los paganos celebran a los suyos por estas acciones heroicas mediante conmemoraciones diversas, los cristianos son tomados por locos porque esperan reconocimiento de su sacrificio por Dios:

En honor de todos ellos alzáis estatuas, inscribís imágenes y grabáis títulos para inmortalizarlos. En la medida que podéis, con los monumentos ofrecéis también vosotros en cierta manera a los muertos la resurrección. ¡Y a quien espera la verdadera de Dios, si padece por Dios, es un loco! ${ }^{33}$.

El final del capítulo y, en consecuencia, del libro presenta una serie de apóstrofes que son toda una llamada a los cristianos a no cejar en su empeño, con una serie de recursos como la anáfora (Quis... Quis), diversas repeticiones (ubi...ubi, ut...ut), o la figura etimológica (accedit ubi accessit):

Pues con su contemplación (de la obstinación), ¿quién no se siente impulsado a investigar qué secreto hay en ella? ¿Quién no lo encuentra cuando lo ha buscado? ¿Quién no desea, cuando lo ha encontrado, sufrir para obtener a cambio toda la gracia de Dios, para conseguir el perdón completo con la compensación de su sangre? ${ }^{34}$.

La obra acaba con una antítesis en forma de quiasmo, que sirve para concluir la argumentación mediante la contraposición de la condena terrenal y la absolución divina: cum damnamur a uobis, a deo absoluimur.

De la misma época que las obras anteriores es Ad martyras, pero de carácter doctrinal, no apologético, ya que sus destinatarios no son paganos, sino cristianos que esperan su martirio en la cárcel. Es una obra mucho más breve, con seis capítulos únicamente, el cuarto de los cuales está dedicado a los ejemplos paganos de heroicidad, entre los que vuelve a hallarse el exemplum de Dido. La argumentación de Tertuliano es simple. Si todos estos personajes, tanto femeninos como masculinos, pues tam-

\footnotetext{
32 Ibidem, 50, 10: O gloriam licitam, quia humanam, cui tantum pro patria, pro imperio, pro amicitia pati permissum est, quantum pro deo non licet!

${ }^{33}$ Ibidem, 50, 11: Et tamen illis omnibus et statuas defunditis et imagines inscribitis et titulos inciditis in aeternitatem. Quantum de monumentis potestis scilicet, praestatis et ipsi quodammodo mortuis resurrectionem. Hanc qui ueram a deo sperat, si pro deo patiatur, insanus est!

${ }^{34}$ Ibidem, 50, 15: Quis enim non contemplatione eius concutitur ad requirendum, quid intus in re sit? Quis non, ubi requisiuit, accedit, ubi accessit, pati exoptat, ut totam dei gratiam redimat, ut omnem ueniam ab eo compensatione sanguinis sui expediat?
} 
bién entre los condenados cristianos hay personas de ambos sexos ${ }^{35}$, fueron capaces de soportar el dolor y el sufrimiento de los peores suplicios por una gloria terrena, ¿cómo no van a ser capaces de hacerlo los mártires cristianos que van a alcanzar la gloria del cielo y la merced divina? Así lo explica al final del capítulo:

Así pues, si sólo por afán de gloria terrenal es posible extraer una fuerza de cuerpo y alma capaz de despreciar la espada, el fuego, la cruz, las bestias y los tormentos, con el único premio de una alabanza humana, puedo decir que esos sufrimientos son poca cosa para la consecución de la gloria celestial y la recompensa divina. ¿Si vale tanto el vidrio, cuánto valdrán las perlas verdaderas? ¿Quién, pues, no pagará por lo verdadero lo que otros pagaron por lo falso ${ }^{36}$.

Como en las obras anteriores, Tertuliano contrapone lo pagano y lo cristiano, en una triple gradación: la gloria terrena con la celestial (terrenae gloriae / gloriae caelestis); la comparación entre algo de poco valor y algo muy preciado, el vidrio y las perlas (vitreum / margaritum); en definitiva, y eso es lo importante, distinguiendo el sacrificio por lo falso del sacrificio por lo verdadero.

Se repiten muchos de los personajes paganos, como no puede ser de otra manera para poner ejemplos cuya finalidad es semejante. Junto con Dido, aparecen en las tres enumeraciones Régulo y la ramera ateniense que se cortó la lengua con los dientes y la escupió al tirano, además de los jóvenes espartanos que se flagelan; coincide con la del Ad nationes en Cleopatra y la mujer de Asdrúbal, y comparte exclusivamente con la lista del Apologeticum los personajes de Mucio y Empédocles. No aparecen en los anteriores un ejemplo clásico romano de castidad, Lucrecia, y otros dos filósofos además de Empédocles, Heráclito, que según la leyenda murió al cubrirse con estiércol para tratar de combatir la hidropesía, y Peregrino, filósofo cínico que se arrojó a las llamas del fuego olímpico el año 165 d.C. en una manifestación extrema de su doctrina.

La enumeración de maneras de morir, gladium, ignem, crucem, bestias, tormenta (Ibidem), es prácticamente igual al primer texto: neque gladios neque cruces neque bestias uestras, non ignem, non tormenta (Tert. Ad nationes 1, 18, 1).

También aparece el exemplum de Dido en otras dos obras de carácter doctrinal, pero posteriores, De exhortatione castitatis y De monogamia. Ambos tratados tienen en común que tratan el tema de las segundas nupcias, de las que nuestro apologeta no era partidario, como se manifiesta especialmente en el segundo, que está más cerca de la

\footnotetext{
${ }^{35}$ En el texto justamente anterior a la enumeración de los exempla así lo dice: nec a viris tantum, sed etiam a feminis, ut vos quoque, benedictae, sexui vestro respondeatis («y tanto entre los hombres como entre las mujeres, para que también vosotras, benditas, respondáis por vuestro sexo») (Tert. Ad Martyras 4, 3, ed. F. Oehler, Tertulliani Opera Quae Supersunt, vol. 1, Leipzig, Weigel, 1853).

${ }^{36}$ Tert. Ad Martyras 4, 9: Igitur si tantum terrenae gloriae licet de corporis et animae vigore, ut gladium, ignem, crucem, bestias, tormenta contemnat sub praemio laudis humanae, possum dicere, modicae sunt istae passiones ad consecutionem gloriae caelestis et divinae mercedis. Si tanti vitreum, quanti verum margaritum? Quis ergo non libentissime tantum pro vero habet erogare, quantum alii pro falso?
} 
herejía montanista ${ }^{37}$. En el primero Tertuliano ensalza la virginidad y la continencia, aunque no está dedicado a una mujer, sino a un amigo que acababa de perder a su esposa. El segundo es mucho más agresivo y en él considera las segundas nupcias ilícitas y cercanas al adulterio: «¿Por qué se nos considera orgullosos por renunciar a quienes no cumplen con la voluntad de Dios? ¿Por qué herejes si juzgamos las segundas nupcias ilícitas y cercanas al adulterio? ¿Qué es el adulterio sino un matrimonio ilícito?» ${ }^{38}$.

Los ejemplos paganos son muy parecidos en ambas obras, como es lógico por la semejanza temática, y aparecen dispuestos en el último capítulo de ambos tratados, como colofón a los argumentos expuestos por Tertuliano en los apartados anteriores. En De exhortatione castitatis los ejemplos paganos de monogamia son presentados de la siguiente manera:

A esta mi exhortación, hermano amantísimo, se añaden también ejemplos profanos, los cuales a menudo se nos han mostrado cuando algo bueno y que complace a Dios también es reconocido y honrado como testimonio por los extranjeros. Los paganos tienen en tan gran honor la monogamia que.... ${ }^{39}$.

Es decir, en ocasiones lo que resulta bueno y placentero a Dios también es reconocido como tal por los profanos, como es el caso de la monogamia, que goza de gran consideración apud ethnicos, denominación que Tertuliano alterna en la misma argumentación con los adjetivos saecularia referido a exempla, y otro sustantivado, extraneis. Así pues, el mundo pagano ofrece muchos ejemplos de defensa de la monogamia que también nos presenta Dios como testimonio. El primer grupo no trata de anécdotas o episodios puntuales de personas particulares, sino de funciones religiosas paganas que exigen la monogamia (Ibidem): la pronuba que unía las manos diestras de los novios era uniuira ${ }^{40}$, y tenía que estar viviendo con su marido en ese momento, porque de ser viuda entrañaría un augurio funesto; la Flaminica y el Flamen Dialis no se podían divorciar, de hecho cuando este perdía a su mujer dejaba de ejercer el cargo, una señal más de la impureza que entrañaba la muerte ${ }^{41}$; tampoco al Pontifex Maximus se le permitía iterare matrimonium.

\footnotetext{
${ }^{37}$ Cfr. E. Monjas Ayuso, «Visión del matrimonio en las obras de Tertuliano: ad uxorem, de exhortatione castitatis y de monogamia» Actas del VIII Congreso Español de Estudios Clásicos II, 1994, pp. 759-776.

${ }^{38}$ De monogamia 15, 1: Quae igitur hic duritia nostra, si non facientibus voluntatem dei renuntiamus? quae haeresis, si secundas nuptias ut illicitas iuxta adulterium iudicamus? Quid est enim adulterium quam matrimonium illicitum? (Ed. V. Bulhart, CSEL 76, Wien, Hoelder-Pichler-Tempsky, 1957).

${ }^{39}$ Tert. De exhortatione castitatis 13, 1: Ad hanc meam cohortationem, frater dilectissime, accedunt etiam saecularia exempla, quae saepe nobis etiam in testimonio posita sunt, cum quid bonum et deo placitum ab extraneis quoque agnoscitur et testimonio honoratur. Denique monogamia apud ethnicos ita in summo honore est, ut... (Ed. H-V. Friedrich, Stuttgart, Teubner, 1990).

${ }^{40}$ Sobre este término y su equivalente griego, $c f r$. J.B. Frey, «La signification des termes $\mu$ óv $\alpha v \delta \rho o \varsigma$ et univira», RecSR 20 (1930), pp. 48-60. Sobre los privilegios religiosos de estas mujeres, cfr. M. Humbert, Le remariage à Rome: étude d'histoire juridique et sociale, Milano, 1972.

${ }^{41}$ En efecto, normalmente esta reticencia religiosa se debía al rechazo del contacto con la muerte exigido para esta clase de funciones, por lo que no se les permitía ejercer a los viudos que estaban manchados por la parca: $c f r$. M.A. Marcos Casquero, «El sacrificio de la mujer viuda en el mundo indoeuropeo», Gerión 19
} 
La virginidad es obligatoria para el segundo grupo de modelos paganos, que también constituyen una relación de representantes religiosos bien conocidos por los romanos de la época como Tertuliano (Novimus... Novimus et...), en su mayoría femeninos (Tert. De exhortatione castitatis 13,2): primero menciona a las Vestales y otras sacerdotisas, obligadas a la castidad en otros templos, Juno en una ciudad aquea, Apolo en Delfos, Minerva y Diana en otros lugares; el único modelo masculino lo constituyen los sacerdotes del buey Apis de Egipto; y por último habla de las mujeres de Ceres Africana, que después de casarse renuncian voluntariamente al sexo y a cualquier contacto físico con el género masculino. Finalmente aduce los ejemplos particulares y por lo tanto heroicos, a diferencia de los anteriores, de Dido y Lucrecia, que se presentan como heroínas por haber preferido la muerte a las segundas nupcias (Ibidem, 13, 3). Este razonamiento es claro en la reina de Cartago, porque: maluit e contrario uri quam nubere «prefirió quemarse que volver a casarse» ${ }^{42}$, pese a que tenía la obligación política (debuerat) como reina de unirse en matrimonio a otro rey, obligación que declinó ne tamen secundas experiretur, «para no hacerlo por segunda vez». Pero en Lucrecia está rebuscado, pues un modelo para el mundo romano de matrona que no quiso sobrevivir a su deshonor lo transforma Tertuliano en un ejemplo de uniuira que no quiso seguir viviendo tras haber mantenido relaciones con un segundo hombre (ne uiueret iam non sibi uniuira), lo que suponía, pese a que su traición se produjo por la fuerza y en contra de su voluntad, dejar de ser monógama a los ojos del cristianismo, y por ello «limpió su carne mancillada con su propia sangre» ${ }^{43}$.

Entre ejemplos y ejemplos, Tertuliano presenta su argumentación: estos modelos indubitablemente positivos que también podemos observar en el mundo profano son provocaciones de Satanás, que trata de confundir a los cristianos y hacer que duden en manifestar su continencia ante Dios porque hay otros que la dedican al diablo, se trate de la virginidad o de la viudedad. Busca así nuestra perdición, tras haberlo hecho a través de la lujuria, mediante la castidad, para que los cristianos la rechacen como instrumento de salvación y agraven su pecado ${ }^{44}$. Los modelos de continencia del pueblo pagano son, pues, tentaciones que el demonio presenta a los cristianos para que duden de la bondad de la castidad.

La conclusión del tratado, sin embargo, establece una clara diferencia a favor de los cristianos respecto a estos ejemplos: además de disponer de mayor cantidad, aunque Tertuliano no los nombre, son mejores «en tanto en cuanto es más valioso vivir en castidad que morir por ella» ${ }^{45}$, razonamiento cuanto menos paradójico para alguien

(2001), pp. 259-292, esp. 262-264. Sobre las obligaciones en el culto de las mujeres paganas romanas, cfr. J. Gagé, Matronalia. Essai sur les dévotions cultuelles des femmes dans l'ancienne Rome, Latomus 60 (1963), pp. 120-124.

42 Como es sabido, aunque la versión conocida es la del libro IV de la Eneida, según la cual se clavó el puñal de Eneas y se arrojó a la pira que había preparado, algunas otras hablan de la muerte de Dido arrojándose a la hoguera.

43 sanguine suo maculatam carnem abluit.

${ }^{44}$ Este mismo argumento se encuentra en Ad uxorem 1, 6 (ed. C. Munier, Paris, Éditions du Cerf, 1980), que también presenta ejemplos de continencia que se hallan en los dos tratados comentados.

${ }^{45}$ Quanto maius est uiuere in castitate quam pro ea mori (Tert. De exhortatione castitatis 13, 3). 
que en otra obra como Ad Martyras ha defendido el martirio como la más gloriosa hazaña; pero en este caso los destinatarios del tratado eran un grupo de confesores que esperaban la muerte en la cárcel y Tertuliano, como buen polemista, pone la retórica al servicio de los intereses concretos de cada discurso.

En De monogamia se hallan los tres mismos grupos de exempla que en De exhortatione castitatis, muy semejantes como vamos a ver, pero en orden diferente, pues primero habla de los ejemplos individuales de Dido y Lucrecia, cuyos nombres no cita en este caso, llamándolas regina Carthaginis y matrona Romana. Los textos que hacen referencia a las historias de ambas contienen muchas descripciones iguales o similares, especialmente los de la primera: profuga in alieno solo; regis nuptias (o al revés) ultro optasse debuisset o debuerat; ne tamen secundas eas experiretur, maluit e contrario uir quam nubere (Tert. De monogamia 17, 2); el episodio de Lucrecia, dividido en tres partes, tiene varios elementos comunes, describiéndose la violación de forma semejante: etsi semel per uim et inuita alium uirum passa est / etsi per vim nocturnam nihilo minus alium virum experta; el suicidio de forma prácticamente igual: sanguine suo maculatam carnem abluit / maculam carnis suo sanguine abluit; y los motivos del mismo: ne uiueret iam non sibi uniuira / ut monogamiam in semetipsam vindicaret (Ibidem, 17, 3).

En segundo lugar hallamos los modelos de la religión pagana de monogamia, que son presentados así: «Ciertamente la monogamia y la viudedad asisten a los ídolos» ${ }^{46}$. La única viudedad, sin embargo, a la que hace referencia Tertuliano en los ejemplos es la de las sacerdotisas de Ceres, las cuales «quedan viudas aun en vida del marido, que acepta una separación amistosa $\gg^{47}$. Por esa razón aquí se incluyen en la lista de monógamas, mientras en De exhortatione castitate forman parte, con mayor lógica, de las paganas entregadas a la castidad. De los ejemplos aportados en esta última obra sólo falta la pronuba, y los únicos añadidos en De monogamia son los cultos matronales de la Fortuna Muliebris y la Mater Matuta, si bien en aquella obra son mencionadas indirectamente: «asimismo, en algunas solemnidades y oficios la mujer monógama ocupa un lugar prioritario» ${ }^{48}$. Los ejemplos de continencia absoluta son prácticamente idénticos, como puede observarse comparando ambos listados:

uirgines Vestae, et Iunonis apud Achaiae oppidum, et Apollinis apud Delphos, et Mineruae et Dianae quibusdam locis. Nouimus et continentes uiros, et quidem tauri illius Aegyptii antistites (Ibidem, 13, 2)

virgines Vestae et Iunonis Achaicae et Dianae Scythicae et Apollinis Pythii; etiam bovis illius Aegyptii antistites (De monogamia 17, 5).

Los modelos religiosos paganos de virginidad femenina presentados son las Vestales, las vírgenes de Juno de una ciudad aquea -se refiere a Aegium, como observa-

\footnotetext{
${ }^{46}$ Ibidem, 17, 4: Idolis certe et monogamia et viduitas apparent.

${ }^{47}$ Ibidem: viventibus etiam viris et consentientibus amica separatione viduantur

${ }^{48}$ Tert. De exhortatione castitatis 13, 1: ut in quibusdam sollemnibus et officiis prior sit uniuirae locus.
} 
mos en otro pasaje de Tertuliano ${ }^{49}-$, las de Apolo en Delfos ${ }^{50}$ o de Apolo Pitio, es decir, las pitonisas, y las de las diosas vírgenes Minerva y Diana en otros lugares, especificando en el segundo texto el famoso templo de Diana en Escitia; entre los ejemplos masculinos de continencia por seguir la religión profana nombra a «los sacerdotes del famoso toro egipcio», el buey Apis cuyo culto siguieron los griegos y romanos.

Aunque los modelos son idénticos, la argumentación retórica del final de $D e$ monogamia es prácticamente inexistente: se trata simplemente de una buscada acumulación de ejemplos paganos de monogamia que sirve para avergonzar a aquellos cristianos que puedan caer en la debilidad de la carne (carnis imbecillitatem). En efecto, serán los modelos paganos de continencia quienes se sentarán a juzgar a los cristianos en el juicio final, como señala el vocabulario referido a los diferentes ejemplos: exurget et decernet in Christianas, assidebit, iudicent, iudicabunt. El tono agresivo y amenazante de Tertuliano va creciendo mediante apóstrofes que pretenden avergonzar a quien caiga en la debilidad de la carne: «iSonrójate, carne que has revestido a Cristo! Que te sea suficiente un único casamiento, para el que fuiste hecho desde el comienzo, para el que eres llamado desde el final $\aleph^{51}$. Acaba el tratado poniendo el ejemplo de Adán; la acumulación de acciones que llevó a cabo en una sola ocasión, destacada mediante la repetición del adverbio semel, como son probar el fruto prohibido, ceder a la concupiscencia, taparse sus partes pudendas, avergonzarse ante Dios, ocultar su vergüenza, salir del Paraíso de la santidad, culmina con la que quiere poner en relieve el autor: nupsit.

También se encuentra la figura de Dido en un tratado polémico, De anima, la segunda obra más extensa de Tertuliano. La cita se inserta en su refutación de la doctrina de la transmigración de filósofos griegos como Pitágoras, Platón y Empédocles, que abarca los capítulos 32 y 33 . Si en el primero pone de relieve lo absurdo que resulta el desarrollo de la teoría de la transmigración de Empédocles que lleva a cabo Pitágoras, en el segundo se burla sin ambages imaginando las diferentes recompensas que cada hombre merecería en su transformación en animal. Tertuliano presenta diversos razonamientos contrarios a la metempsicosis, el primero de ellos: si las almas se transforman, no pueden recibir el trato que han merecido, no pueden ser juzgadas porque no pueden rendir cuentas a Dios de sus actos. A continuación va imaginando la sinrazón e injusticia que comportará siempre cualquier transformación que puede sufrir un hombre según sus actos, con la pretensión de burlarse de semejante doctrina: el alma del homicida deberá pasar al de un animal destinado a ser sacrificado de la misma manera que él ha hecho, y si su acción ha sido especialmente cruel, sin duda preferirá la sentencia de los partidarios de la metempsicosis: «Si pensamos la recompensa para los restantes crímenes, la horca, la hoguera, el saco de cuero, los garfios, las rocas afiladas, ¿a quién no le conven-

\footnotetext{
49 Ad uxorem 1, 6, 4: Achaicae Iunoni apud Aegium oppidum uirgo sortitur.

${ }^{50}$ Las pitonisas de Delfos son descritas así en el mismo pasaje: quae Delphis insaniunt nubere nesciunt (Ibidem).

${ }^{51}$ Tert. De monogamia 17, 6: Embesce, caro, quae Christum induisti! Sufficiat tibi semel nubere, in quod a primordio facta es, in quod e fini revocaris.
} 
dría sufrir su sentencia en Pitágoras y Empédocles?» ${ }^{52}$. En cambio, la recompensa para aquellos que han llevado una vida íntegra y virtuosa será reencarnarse en un animal: «¡Magnífica recompensa para los hombres de bien, revivir en el cuerpo de cualquier animal!» ${ }^{53}$. Ennio soñó que Homero recordaba haber sido un pavo real, «pero no creería yo a los poetas ni despiertos» ${ }^{54}$. Los poetas, pues, serían todos pavos reales o cisnes, pues son autores de hermosas composiciones y deben transformarse en hermosos animales, pero Tertuliano busca reconducir el argumento a sus intereses utilizando la burla y el sarcasmo:

Por muy hermoso que sea un pavo real y muy adornado por el brillo de sus colores, sus plumas son mudas, su voz desagradable, y nada es más preferible para los poetas que cantar. Se ha castigado, pues, a Homero, no se le ha premiado al transformarlo en pavo real. Disfrutará más de la recompensa de los paganos, que lo consideran padre de las disciplinas liberales, prefiriendo los ornamentos de su fama a los de su cola ${ }^{55}$.

Y aquí es donde Tertuliano introduce el personaje de Dido, junto con el de Éaco, famoso por su buen juicio y designado juez de las sombras a su muerte, empleando el razonamiento deductivo-silogístico que tanto le complace:

De acuerdo, que los poetas se transformen en pavos reales o en cisnes; si la voz de los cisnes es elegante, ¿con la piel de qué animal revestirás al justo Éaco? ¿Con la de qué bestia a la casta Dido? ¿Qué ave le tocará en suerte a la paciencia, qué res a la santidad, qué pez a la inocencia? Todos los seres vivos son esclavos del hombre, todos le están sometidos, todos le sirven. Si se va a convertir en uno de ellos, se menosprecia a aquel que es recompensado por los méritos de su vida con imágenes, estatuas, títulos, honores públicos y privilegios, a aquel a quien la curia y el pueblo ofrecen sacrificios ${ }^{56}$.

El texto utiliza la figura de la concesión, tan del gusto de Tertuliano, encabezada con la exclamación age nunc. En el argumento silogístico que rige la argumentación para conducir al absurdo la filosofía que critica, las oraciones condicionales y las inte-

\footnotetext{
52 Tert. De anima, 33, 6: Si ceterorum quoque scelerum mercedem cogitemus, patibula et uiuicomburia et culleos et uncos et scopulos, cui non expediat apud Pythagoran et Empedoclen sententiam pati? (Ed. J.H. Waszink, CC, Series Latina II, Turnhout, Brepols, 1954).

${ }_{53}$ Ibidem, 33, 7: Nimirum magna merces bonis in animalia quaecumque restitui.

${ }^{54}$ Ibidem, 33, 8: sed poetis nec uigilantibus credam.

${ }^{55}$ Ibidem: Et si pulcherrimus pauus et quo uelit colore cultissimus, sed tacent pennae, sed displicet uox, et poetae nihil aliud quam cantare malunt. Damnatus est igitur Homerus in pauum, non honoratus. Plus de saeculi remuneratione gaudebit, pater habitus liberalium disciplinarum, ut malit famae suae ornamenta quam caudae.

${ }^{56}$ Ibidem, 33, 9: Age nunc, ut poetae in pauos uel in cycnos transeant, si uel cycnis decora uox est, quod animal indues uiro iusto Aeaco? Quam bestiam integrae feminae Didoni? Quam uolucrem patientia, quam pecudem sanctimonia, quem piscem innocentia sortientur? Omnia famula sunt hominis, omnia subiecta, omnia mancipata. Si quid horum futurus est, diminoratur illic ille cui ob merita uitae imagines, statuae et tituli, honores publici, priuilegia rependuntur, cui curia, cui populus suffragiis immolat.
} 
rrogaciones son las herramientas básicas que utiliza, pues las diferentes condiciones llevan a conclusiones rocambolescas y las interrogaciones son el modo retórico de destacar esa sinrazón.

\section{JERÓNIMO DE ESTRIDÓN}

La figura de Dido también aparece en dos textos de Jerónimo. En una carta exhorta a Ageruquia, una joven viuda, a no contraer segundas nupcias, con unos ejemplos históricos y legendarios semejantes a los de Tertuliano, como vamos a observar, que incluyen a Dido. El argumento que precede a los ejemplos paganos es el siguiente: «También los paganos observan esta ley, para condenar a los nuestros si la verdad no manifiesta a Cristo lo que la mentira atribuye al diablo, que inventa una castidad condenatoria ${ }^{57}$. Coincide con el De exhortatione castitatis de Tertuliano tanto en los ejemplos que acompañan a Dido como en el argumento, muy escueto aquí, según el cual es el demonio quien incluye estas acciones en el mundo pagano para evitar que los cristianos sigan su modelo, lo que le hace tomar del polemista africano el término castitatem perditricem (Tert. De exhortatione castitatis 13, 2). Los ejemplos paganos presentados por Jerónimo que coinciden con Tertuliano son los de la monogamia del Flamen y su mujer, los sacerdotes del buey Apis, y los de la castidad de las vírgenes de Vesta, Apolo, Juno Aquea, Diana y Minerva, dejando también para después los casos de Dido y de Lucrecia, entre los que se encuentra el de la mujer de Asdrúbal, que leemos junto con el de la reina cartaginesa en los ejemplos de Tertuliano de Ad nationes y Ad martyras. A diferencia de los textos de Tertuliano, en que se limita a hablar de un genérico regis, Jerónimo nombra explícitamente a Jarbas, y el único ejemplo novedoso de monogamia es el del hierofante, sumo sacerdote del culto de Eleusis: «En Atenas el hierofante renuncia a su virilidad y se hace impotente para ser siempre casto ${ }^{58}$. Tras presentar estos exempla no ofrece argumento alguno, como dice explícitamente, se limita a remitir al primer libro Contra Joviniano, en el que se encuentra la otra cita de Dido, y acaba con un último exemplum de las mujeres de los teutones que, al ser derrotado el ejército de sus maridos, prefirieron dar muerte a sus hijos y ellas mismas murieron abrazadas: «para que sepas que incluso entre los bárbaros y los pueblos fieros y sanguinarios es respetada la castidad» ${ }^{59}$. Este ejemplo corresponde pues, no a ejemplos griegos o romanos, sino bárbaros, que aún son menos civilizados y por lo tanto tienen más valor, como dejan claro los adjetivos que dedica a estas gentes.

\footnotetext{
${ }^{57}$ Ieron. Ad Ageruchiam 123, 8: Quod quidem obseruat, et gentilitas, in condemnationem nostri, si hoc non exhibeat ueritas Christo, quod tribuit mendacium diabolo; qui et castitatem reperit perditricem (Ed. J. Labourt, Saint Jérôme. Correspondance. tome VII, Lettres CXXI-CXXX, Paris, Les Belles Lettres, 1949-63).

${ }^{58}$ Ieron. Ad Ageruchiam 123, 8: Hierophanta apud Athenas eiurat uirum, et aeterna debilitate fit castus.

${ }^{59}$ Ibidem: ut scias pudicitiam etiam barbaris ac feris, et sanguinariis gentibus esse uenerabilem.
} 
En el tratado polémico Adversus Iouinianum, que sirve para refutar las opiniones de Joviniano por poner en discusión el valor de la virginidad y la vida ascética ${ }^{60}$, aparece una cita de Dido, quien constituye la referencia básica para la tradición eclesiástica de la figura de la reina cartaginesa como exemplum de monogamia ${ }^{61}$, y encabeza la lista de viudas paganas que no quisieron sobrevivir a la muerte de sus esposos. Los dos exempla de Jerónimo que tratan sobre Dido tienen el episodio de la mujer de Asdrúbal como colofón, que sirve para comparar dos casos semejantes en la fundación y la destrucción de Cartago. Tras haber enumerado una gran cantidad de vírgenes heroínas de la mitología y la leyenda, la reina cartaginesa es el exemplum que encabeza las viudas. El motivo de hacer una enumeración de ejemplos de virginidad entre los paganos es explicado así por Jerónimo:

Hemos entresacado de los libros sagrados ejemplos más que suficientes de castidad cristiana y de virginidad angelical. Pero ya que he entendido en los comentarios de mi adversario que recurrimos a la sabiduría del mundo, género que nunca ha sido demostrado en el siglo, y nuestra religión ha proporcionado un nuevo dogma contra la naturaleza, recurriré con brevedad a las historias griegas, latinas y bárbaras y demostraré que la virginidad siempre ha tenido la primacía de la castidad ${ }^{62}$.

Después de los ejemplos de las Sagradas Escrituras, pasa a hacerlo de las historias griegas, latinas y bárbaras ${ }^{63}$ para refutar a Joviniano, que afirma que la castidad y la virginidad son exclusivas del cristianismo (novum dogma contra naturam religio nostra prodiderit) y para demostrar que siempre han formado parte de los principios de los paganos. La lista es ciertamente extensa, pese a que Jerónimo afirme lo contrario (percurram breviter Graecas et Latinas barbarasque historias), no sabemos si por burla o por hipérbole, desde este mismo capítulo 41 hasta el 43, que inicia la lista de las viduae gentiles con Dido y la mujer de Asdrúbal, para seguir con las griegas y bárbaras y pasar en el 46 a las mujeres insignes romanas, encabezadas por Lucrecia: Ad Romanas feminas transeam; et primam ponam Lucretiam. En los capítulos 47 y 48 enumera los aspectos negativos de la vida matrimonial y las ventajas del celibato, para acabar elogiando la pudicitia en el 49; se basa en gran medida en citas de Séneca y repite cono-

\footnotetext{
${ }^{60} \mathrm{Cfr}$. F. Corsaro, «I concili di Roma e di Milano del 390 e l'Adversus Iovinianum di Gerolamo intorno al tema verginità/matrimonio», en I concili della cristianità occidentale, sec. III-V, Roma, 2002, pp. 447-460; J. Torres, «La historia de un monje hereje: Joviniano y el conflicto entre matrimonio y virginidad en el siglo IV», en M.M. Marcos (ed.), Herejes en la historia, Madrid, 2009, pp. 49-76.

${ }^{61} C f r$. M.R. Lida de Malkiel, op. cit., p. 79.

${ }^{62}$ Ieron. Adv. Iov. 1, 41: Satis abundeque Christianae pudicitiae et virginitatis angelicae, de divinis Libris exempla praebuimus. Sed quoniam intellexi in Commentariis adversarii, provocari nos etiam ad mundi sapientiam, quod nunquam hoc genus in saeculo sit probatum, et novum dogma contra naturam religio nostra prodiderit, percurram breviter Graecas et Latinas barbarasque historias, et docebo virginitatem semper tenuisse pudicitiae principatum (Ed. M. Marcos Celestino - M.A. Marcos Casquero, Obras completas de San Jerónimo. VIII: Tratados apologéticos, Madrid, BAC, 2009).

${ }^{63}$ Sobre estos ejemplos, $c f r$. D.F. Heimman, «The Polemic Application of Scripture in St. Jerome», Studia Patristica 12 (1975), pp. 309-316; B. Clausi, «La parola straniata. Polemica ed esegesi biblica nell'Adversus Iovinianum di Gerolamo», Vetera Christianorum 32 (1995), pp. 21-60.
} 
cidos ejemplos paganos de la exigencia de castidad y de monogamia, como en los cargos religiosos o las mujeres dedicadas al culto de la Fortuna Muliebris, los Flamines o los Hierophantes. También proporciona ejemplos de figuras históricas como Cornelia, madre de los Gracos, Porcia, la mujer de Bruto, o la propia Lucrecia ${ }^{64}$. Jerónimo seguía así una estrategia retórica altamente efectiva por su carácter emocional, consistente en exhortar a sus lectoras a practicar la pudicitia a imitación de mujeres reales presentadas en gran parte de las obras de Séneca, y no de la historia eclesiástica, porque ellas pertenecían a la aristocracia romana y, consecuentemente, su sentimiento de identidad nacional era romano y conocían bien las historias de estos modelos femeni$\operatorname{nos}^{65}$. Se ha tratado de reconstruir parcialmente el pequeño tratado de Séneca De matrimonio a partir del Adversus Iovinianum, lo que ha servido para estudiar el probable influjo del estoicismo en el tratado de Jerónimo ${ }^{66}$.

\section{AGUSTÍN DE HIPONA}

Habla de Dido también Agustín en sus Confessiones, su obra autobiográfica, al explicar los gustos errados de su niñez en el capítulo I. Nos confiesa que odiaba las letras griegas, pero amaba las latinas, aunque no las primeras letras que sirven para aprender a leer y escribir, que tampoco le gustaban (Aug. Conf. 1, 13, 2067). Y se lamenta de sus preferencias teniendo en cuenta su conversión, pues las primeras letras le han dado la posibilidad de leer y escribir lo verdaderamente importante, ahora que ha hallado el camino correcto. Los errados rumbos le conducían a la muerte y le apartaban de Dios, como era el gusto por las letras paganas, representadas por los amores de Dido y Eneas (Ibidem, 1, 13, 20-21). En el texto se hallan recursos retóricos como la contraposición entre conceptos como la muerte que significa el mundo pagano en general y Dido en particular, y vita mea, apóstrofe con el que Agustín se dirige a Dios: «yo lamentaba la muerte de Dido, porque se mató por amor, mientras yo mismo moría porque estas historias me alejaban de ti, Dios, vida mía» ${ }^{68}$. También aparecen juegos de palabras, con la semántica de error, que en su sentido etimológico significa ruta equivocada, extravío, a la que hacen referencias los errores de Eneas en su ruta desde Troya hasta Italia ${ }^{69}$, y los propios de Agustín, de significado religioso: «yo aprendía por la fuerza los viajes errantes de no sé qué Eneas, olvidándome de mis propios errores» ${ }^{70}$.

\footnotetext{
${ }^{64}$ Sobre la influencia de Séneca en el Adversus Iovinianum, cfr. P.A. Molina, Jerome's Role in the Transmission of the Correspondence between Seneca and Paul, Chapel Hill, 2011, pp. 34-49.

${ }^{65}$ Cfr. P.A. Molina, op. cit., p. 45.

${ }^{66}$ I. Ramelli, en «La tematica de matrimonio nello Stoicismo romano: alcune osservazioni» Ilu 5 (2000), pp. 145-162, plantea la influencia del neoestoicismo y en particular de Musonio y sus Dissertationes en el pensamiento cristiano sobre el matrimonio, empezando por Clemente de Alejandría.

${ }^{67}$ Ed. M. Skutella, Stuttgart, Teubner, 1969.

${ }^{68}$ Ibidem, 1, 13, 20: Plorare Didonem mortuam, quia se occidit ab amore, cum interea me ipsum in his a te morientem, deus, vita mea.

69 Poco después vuelve a jugar con la doble acepción de los Aeneae errores (Ibidem, 1, 13, 22).

${ }^{70}$ Ibidem, 1, 13, 20: tenere cogebar Aeneae nescio cuius errores, oblitus errorum meorum.
} 
Las repeticiones y juegos de palabras vuelven aún con mayor audacia en el parágrafo posterior, especialmente en la expresión: «¿qué cosa más digna de compasión que un hombre digno de compasión que no se compadecía de sí mismo?» ${ }^{71}$, precedida en el final del parágrafo anterior por otro miserrimus, para reiterar la desgracia de alguien como él por estar apartado de Dios en esta época. Las expresiones paralelas contraponen ambos mundos, como se observaba en Tertuliano: «(la muerte de Dido) que ocurría por amar a Eneas [...] (la muerte propia) que ocurría por no amarte (a Dios) $\rangle^{72}$, siendo en este caso Eneas el representante del mundo pagano; flente Didonis mortem [...] non flente autem mortem suam, contrasta el lamento por una muerte ficticia, con la ausencia de lamento por la propia muerte, que constituye el alejamiento de Dios. Esta idea se repite con el mismo verbo más adelante: «no me compadecía de esto y me compadecía de Dido ${ }^{73}$, insistiendo en contraponer miembros precedidos o no por la negación (amando / non amando, flente / non flente, flebam / non flebam). No amar a Dios significaba su propia muerte: mortem suam, quae fiebat non amando te, y también una traición a su matrimonio con Dios, por lo que la lectura de las obras paganas constituiría un adulterio, como refleja la llamativa expresión «no te amaba, y te era infiel, y siéndote infiel $[\ldots]\rangle^{74}$. Se observa de nuevo el uso aberrante del ablativo separativo abs te en dependencia del verbo fornicor, como antes lo había hecho en a te morientem, uso que sirve a Agustín para plasmar la imagen del alejamiento de Dios, o bien como una forma de muerte, o mediante las relaciones ilícitas de este caso, reacción aberrante que repite nuevamente en dependencia del sustantivo verbal: «pues el amor con este mundo es una infidelidad hacia ti $\rangle^{75}$; y una vez más contraponiendo el mundo pagano con Dios: mundi huius / te.

Hay numerosas repeticiones, la mayoría para crear juegos de palabras y buscar la sorpresa conceptual: Didonem... extrema secutam, sequens ipse extrema contrasta el seguimiento excesivo de Dido por el amor de Eneas y del joven Agustín por estas historias paganas; la expresión terra iens in terram es un juego de palabras que contrasta su actitud terrenal con el precedente relicto te, pues tenía abandonado a Dios. Las expresiones rebuscadas basadas en repeticiones y juegos conceptuales continúan: «si se me impedía leer tales cosas, me dolía porque no leía lo que me dolía» ${ }^{76}$; se vale de la semántica del verbo doleo para hacer un juego de palabras con el sufrimiento de no poder leer los libros paganos y el sufrimiento que le causaban los mismos. Es interesante observar cómo acaba Agustín este capítulo 13 sobre sus aficiones, ya que en el último parágrafo repite una idea que pasó de los Padres de la Iglesia a la Edad Media e incluso más allá, como es la falsedad del paso de Eneas por Cartago y sus amores con Dido, es decir, la versión de Virgilio, porque ello supone desmentir los

\footnotetext{
${ }^{71}$ Ibidem, 1, 13, 21: quid enim miserius misero non miserante se ipsum.

72 quae fiebat amando Aenean [...] quae fiebat non amando te.

${ }^{73}$ haec non flebam, et flebam Didonem.

74 non te amabam, et fornicabar abs te, et fornicanti [...]

75 amicitia enim mundi huius fornicatio est abs te.

${ }^{76}$ si prohiberer ea legere, dolerem, quia non legerem quod dolerem.
} 
valores de la reina cartaginesa que hemos visto como modelo en los textos anteriores: «si yo les pregunto si es verdad lo que dice el poeta de que Eneas fue alguna vez a Cartago, los más incultos me responderán que no lo saben, pero los más cultos negarán que eso sea cierto» ${ }^{77}$.

\section{CONCLUSIONES}

Los exempla de Dido y otros personajes paganos son utilizados, pues, como estrategia de persuasión en diferentes ocasiones por Tertuliano; en las obras apologéticas Ad nationes y Apologeticum le sirven de comparación con los exempla de los mártires cristianos, para demostrar mediante argumentos silogísticos ante los ciudadanos romanos o ante los gobernadores de provincias, todos ellos paganos, la injusticia que supone el diferente trato que merecen actos de la misma naturaleza. Estas obras, que tienen el formato de un discurso judicial de defensa, especialmente la segunda por su mayor elaboración y por los destinatarios, sirven para que Tertuliano defienda como abogado una causa del pasado como son las acciones que han llevado a cabo los mártires cristianos ${ }^{78}$.

A diferencia de las apologías, el discurso de las obras doctrinales es exhortativo, pues va dirigido a los cristianos. El tratamiento en Ad martyras es diferente a los dos tratados posteriores porque el motivo de la escritura es más ocasional, más perentorio, animar al martirio a unos condenados a muerte, aunque también De exhortatione castitatis haya sido escrita por una causa concreta; además, forma parte de sus primeras obras, de estilo más llano y directo, es más breve y no tiene la misma densidad doctrinal. El argumento de su discurso exhortativo presupone la superioridad moral de las acciones de los cristianos, a quienes va dirigido: si los paganos han sido capaces de realizar esta clase de actos y sacrificar su vida por motivos vanos, ¿cómo no van a poder hacer lo propio ellos por la causa de Dios? En De exhortatione castitatis y De monogamia, al tratarse de tratados doctrinales más elaborados y de un carácter menos directo y sencillo, los exempla paganos de castidad y monogamia son presentados como tentaciones que pone el diablo ante los ojos de los cristianos para que comparen y duden en actuar de la misma manera que los paganos, y también para que los creyentes se avergüencen de no comportarse como lo hacen otros que no lo son. Es un recurso persuasivo que Tertuliano emplea para exhortar a los cristianos a la castidad y a la monogamia, esta última en un sentido amplio de la expresión que abarca también el rechazo a las segundas nupcias.

El personaje de Dido en un tratado polémico como De anima es un recurso más de Tertuliano para poner en ridículo ciertas doctrinas filosóficas, que sirvieron de caldo de cultivo a diferentes herejías. En concreto el pasaje donde aparece la reina de Car-

\footnotetext{
${ }^{77}$ Ibidem, 1, 13, 22: si proponam eis interrogans utrum verum sit quod Aenean aliquando Carthaginem venisse poeta dicit, indoctiores nescire se respondebunt, doctiores autem etiam negabunt verum esse.

${ }^{78}$ Esta es la función de los exempla en los discursos judiciales: cfr. F. Vera, op. cit., p. 194.
} 
tago satiriza la doctrina pitagórica de la metempsicosis para tratar de utilizar sus argumentos y llevarlos al absurdo. La utilización de Dido es absolutamente diferente a los otros pasajes de Tertuliano, pues no sirve de comparación con los modelos cristianos que imitan las mismas cualidades de la casta reina cartaginesa.

Los dos ejemplos de Dido que aparecen en Jerónimo tienen una función muy distinta. En la carta 123 dirigida a Ageruquia se sirve de los mismos argumentos de persuasión, e incluso de los mismos términos, castitatem perditricem, que Tertuliano en sus dos tratados doctrinales, en los que intenta disuadirla para que no contraiga segundas nupcias, animando a la castidad aunque también represente un valor propio del mundo pagano y bárbaro. El tratado polémico antiherético In Iovinianum representa el ejemplo paradigmático de utilización como modelo de monogamia del personaje de Dido, que goza de una posición preeminente al encabezar la enumeración de las viudas paganas que no aceptaron las segundas nupcias, y desarrollar la historia sin limitarse a pasar con rapidez por ella; los exempla de castidad y monogamia son muy abundantes, y Jerónimo recurre a los diferentes mundos paganos griego y romano e incluso a los bárbaros, porque trata de argumentar que las cualidades mencionadas son comúnmente aceptadas como positivas y no una creación dogmática de los cristianos; tiene en cuenta, además, el auditorio al que va dirigido, que conoce mejor estos modelos por formar parte de su nación, que los de la historia eclesiástica en la que se acababan de iniciar.

Finalmente, pasa revista a sus aficiones literarias de juventud Agustín en sus Confessiones y reconoce lo errado que estaba al amar, como lo hacía, las historias de Dido y Eneas, siendo el único autor que nombra explícitamente al héroe troyano, ya que en los demás casos citarlo sería reconocer la falta de veracidad de la versión que representa la figura de la reina cartaginesa como modelo de monogamia. La Eneida de Virgilio es en este caso un ejemplo de las obras que tanto le agradaban de joven, lo que le sirve para destacar lo errado de su camino, al llorar y sentir emociones por semejante literatura, mientras no se daba cuenta de que estaba apartado del verdadero camino hacia Dios.

El ejemplo de Dido y de otros personajes del mundo pagano, aceptando el sufrimiento en defensa de la castidad o la monogamia sirven a los polemistas cristianos como materia argumentativa, más como contraste con los exempla cristianos que modélica per se, un contraste que es la base de los recursos retóricos que utilizan para persuadir. En efecto, entre estos siempre destaca la comparación entre el mundo pagano y el mundo cristiano; si se trata de obras apologéticas dirigidas a paganos, son abundantes los contrastes entre «vosotros» y «vuestro», frente a «nosotros» y «nuestro», y la retorsio argumentorum sirve para poner de manifiesto la injusticia y sinrazón del trato a los mártires cristianos; si son obras doctrinales escritas para instruir a los fieles, se les exhorta a no dejar de seguir los buenos ejemplos porque estos correspondan a infieles, pues es el diablo quien presenta tales modelos para que los cristianos no consideren positivas estas acciones y no las sigan por considerarlas impropias; en las obras polémicas contra otras herejías encontramos la burla y el sarcasmo para destacar lo erróneo y desviado de estas posturas, o un razonamiento dogmático 
según el cual la presencia y abundancia de exempla de las más diversas procedencias, por muy alejadas que estén de la doctrina cristiana, ponen de manifiesto que no son invenciones de la misma valores como la monogamia y la castidad. La confesión de Agustín contrasta su errado pasado con los viajes de Eneas y sus amores con Dido, que le mantenían alejado del camino correcto hacia Dios. 